\title{
Coping strategies, hope, and treatment efficacy in pharmacoresistant inpatients with neurotic spectrum disorders
}

This article was published in the following Dove Press journal:

Neuropsychiatric Disease and Treatment

15 May 2015

Number of times this article has been viewed

\author{
Marie Ociskova ${ }^{1,2}$ \\ Jan Prasko \\ Dana Kamaradova ${ }^{2}$ \\ Ales Grambal ${ }^{2}$ \\ Petra Kasalova ${ }^{2}$ \\ Zuzana Sigmundova ${ }^{2}$ \\ Klara Latalova ${ }^{2}$ \\ Kristyna Vrbova ${ }^{2}$ \\ 'Department of Psychology, Faculty \\ of Arts, ${ }^{2}$ Department of Psychiatry, \\ Faculty of Medicine and Dentistry, \\ Palacky University Olomouc, \\ University Hospital Olomouc, \\ Olomouc, Czech Republic
}

Background: Approximately $30 \%-60 \%$ of patients with neurotic spectrum disorders remain symptomatic despite treatment. Identifying the predictors of good response to psychiatric and psychotherapeutic treatment may be useful for increasing treatment efficacy in neurotic patients. The objective of this study was to investigate the influence of hope, coping strategies, and dissociation on the treatment response of this group of patients.

Methods: Pharmacoresistant patients, who underwent a 6-week psychotherapeutic program, were enrolled in the study. All patients completed the Clinical Global Impression (CGI) - both objective and subjective forms, Beck Anxiety Inventory (BAI), and Beck Depression Inventory (BDI)-II at baseline and after 6 weeks. The COPE Inventory, the Adult Dispositional Hope Scale (ADHS), and the Dissociative Experiences Scale (DES) were completed at the start of the treatment.

Results: Seventy-six patients completed the study. The mean scores for all scales measuring the severity of the disorders (BAI, BDI-II, subjective and objective CGI) significantly decreased during the treatment. Several subscores of the COPE Inventory, the overall score of ADHS, and the overall score of DES significantly correlated with the treatment outcome. Multiple regression was used to find out which factors were the most significant predictors of the therapeutic outcomes. The most important predictors of the treatment response were the overall levels of hope and dissociation.

Conclusion: According to our results, a group of patients with a primary neurotic disorder, who prefer the use of maladaptive coping strategies, feel hopelessness, and have tendencies to dissociate, showed poor response to treatment.

Keywords: neurotic spectrum disorders, treatment efficacy, dissociation, coping strategy, hope

\section{Introduction}

Neurotic spectrum disorders are highly prevalent mental disorders. We used the term "neurotic spectrum disorders" to cover the whole ICD-10 category "Neurotic, stressrelated and somatoform disorders (F40-F48)". ${ }^{1}$ This group includes Phobic anxiety disorders; Other anxiety disorders; Obsessive-compulsive disorder (OCD); Reaction to severe stress, and adjustment disorders; Dissociative [conversion] disorders; Somatoform disorders; and Other neurotic disorders. Most of the general therapeutic strategies used in these groups of patients are the same, but it is true that some therapeutic strategies are specific for certain diagnoses (eg, exposure with response prevention in OCD and hypochondriasis, trauma processing in posttraumatic stress disorder (PTSD), exposure to catastrophic scenarios in somatoform disorders). This ICD-10 category is dispersed in $D S M-5^{2}$ into several categories (Anxiety disorder, Obsessive-compulsive and related disorders, Trauma- and stress-related disorders, Dissociative disorders, and Somatic symptom and related disorders) and there are several differences between
Correspondence: Jan Prasko Department of Psychiatry, University Hospital Olomouc, I.P. Pavlova 6, 77520 Olomouc, Czech Republic Tel +420588443513

Email praskojan@seznam.cz
Neuropsychiatric Disease and Treatment 2015:II |19|-1201 (c) () () 2015 Ociskova et al. This work is published by Dove Medical Press Limited, and licensed under Creative Commons Attribution - Non Commercial (unported, v3.0) License. The full terms of the License are available at http://creativecommons.org/licenses/by-nd/3.0/. Non-commercial uses of the work are permitted without any further Dedical Press Limited, provided the work is properly attributed. Permissions beyond the scope of the License are administered by Dove Medical Press Limited. Information on how to request permission may be found at: http://www.dovepress.com/permissions.php 
both diagnostic manuals in each concrete diagnostic criteria. Neurotic spectrum disorders have a potential to be chronically disabling if untreated. ${ }^{3}$ Both pharmacological and psychotherapeutic approaches have proven their effectiveness in the treatment of the neurotic spectrum disorders. ${ }^{4,5}$ However, approximately $30 \%-60 \%$ of the patients remain symptomatic after treatment. ${ }^{6,7}$ Many studies focused on sociodemographic factors that may positively influence treatment response. ${ }^{8}$

Dissociation proved to be one of the important psychological factors, which could be connected with inadequate treatment response. ${ }^{9}$ Dell and O'Neil defined dissociation in terms of dysfunction in the integration of perception, memory, cognition, emotions, or somatic reactions. ${ }^{10}$ Dissociation is seen as a defense mechanism used to deal with unbearable emotional states. ${ }^{11,12}$ Dissociation prevents the natural integration of threatening experiences and information and can be characterized by amnesia, depersonalization, or derealization. ${ }^{13}$ Individuals, who use dissociation as a preferred defense mechanism, often have a history of child abuse or other childhood trauma. ${ }^{14}$ Dissociative symptoms may also be the byproducts of a labile sleep-wake cycle. ${ }^{15}$ While a certain level of dissociative experiences are nonpathologic or even beneficial (such as the experiences of "flow"16), the excessive experience of dissociative phenomena may lead to dissociative disorders. The exact prevalence of dissociative disorders is not known, partially because dissociative disorders often remain unrecognized by psychiatrists. ${ }^{17}$ Thus, the prevalence can only be estimated in a broad range as $5.6 \%-10 \% .{ }^{10}$ A certain degree of the symptoms of dissociation are common in the majority of patients with mental disorders. Patients with anxiety or neurotic spectrum disorders are no exception. ${ }^{18-20}$ Dissociation is common in patients with panic disorder, ${ }^{19} \mathrm{OCD},{ }^{20,21}$ borderline personality disorder, ${ }^{22,23}$ and, certainly, dissociative disorders. ${ }^{24}$ As has been shown by Sar and Ross, ${ }^{25}$ the dissociative symptoms might affect the course of mental disorders. Others found that higher levels of dissociation are one of the causes of treatment failure in patients with panic disorder ${ }^{18,26,27}$ and OCD. ${ }^{20,21}$ Research on dissociation in OCD showed that more severe OCD symptoms after cognitive behavioral therapy (CBT) were associated with higher Dissociative Experiences Scale (DES) scores at baseline, and treatment nonresponders had significantly higher baseline DES scores compared to responders. ${ }^{21}$ However, not all findings considering the influence of dissociation on treatment efficacy in neurotic spectrum patients are consistent. For example, according to Hagenaars et $\mathrm{al}^{28}$ the level of dissociation may not affect treatment outcomes in patients with PTSD.
On the other hand, Simeon et $\mathrm{al}^{29}$ and Vásquez et $\mathrm{al}^{30}$ found that persistent dissociation is one of the factors which predict poor prognosis in patients with PTSD.

Dissociation is connected to coping strategies, such as substance abuse or disengagement. ${ }^{31,32}$ Also, avoidant coping strategies negatively affect the course of anxiety disorders. ${ }^{33}$ Prevalent use of mental forms of avoidance (suppression) are maladaptive as well (Campbell-Sills et al unpublished data, 2003). ${ }^{34}$ On the other hand, reappraisal, another frequently used coping strategy, seems to be thoroughly beneficial. ${ }^{35}$ Little is known about the effect of other coping strategies in the course of neurotic disorders and their treatment.

Another important factor contributing to the efficacy of psychotherapy is hope. Traditionally, hope has been seen as a passive factor present to some extent in every person, a factor that contributes to treatment efficacy. ${ }^{36}$ However, the ways and means of the influence of hope on treatment efficacy have been unclear. ${ }^{37}$ Hope has also sometimes been a target of criticism by some scientists, who considered hopeful feelings naïve or unrealistic. ${ }^{38}$ Thus, hope is a rather controversial topic. Snyder ${ }^{39,40}$ created a theory of hope which was based on cognitions, motivation, or behavior, and not solely on the emotion of hope. This theory has become one of the most influential theories of hope over the years. Snyder defined hope as "a positive motivational state that is based on an interactively derived sense of successful (a) agency (goal-directed energy) and (b) pathway thinking (planning to meet goals)". ${ }^{39}$ Despite psychodynamic theories, which highlight that hope is mainly an emotion, Snyder considered hope as a multifactorial phenomenon. He stated that hope cannot be present without goals. One cannot feel or think hopefully if he or she does not have something to strive or wish for. The author also stated that individuals who often feel hopeful are those who can find ways to achieve those desired goals. Finally, these individuals need to have a satisfactory level of motivation (ie, agency) to follow paths to reach the goals and to be flexible if the plans need to be changed. ${ }^{39}$

Hopeful feelings or hope as an overarching concept is learned through life. The number of successfully reached goals and problems solved increase the level of hope. ${ }^{41}$ Thus, a person may increase his baseline level of hope during life. It may decrease as well. Hope predicts use of some coping strategies. Kwon ${ }^{38}$ showed that individuals low in hope prefer avoidant coping strategies while hopeful individuals use more adaptive coping strategies, such as seeking social support, reaching an active solution of the stressful situation, or using humor. Fostering hope is an important issue in cases 
of chronically or terminally ill patients or in patients who suffer from severe mental disorders, such as dementia ${ }^{42}$ or psychoses. ${ }^{43}$ However, increasing or maintaining hope is also important in other fields of medicine and clinical psychology. The specific effects of hope on the course and efficacy of psychotherapy are yet to be uncovered.

This research was planned as a pilot study and its purpose was to explore the influence of hope, coping strategies, and dissociation on treatment efficacy in patients with neurotic disorders with or without comorbid depressive or personality disorders. Our hypotheses were that high levels of dissociation and use of maladaptive coping strategies decrease treatment efficacy and high levels of hope increase treatment efficacy of combined psychotherapy and pharmacotherapy in patients with neurotic spectrum disorders.

\section{Methods}

Patients suffering from neurotic spectrum disorders, referred to the intensive inpatient therapeutic program because of pharmacy resistance, were enrolled in the study. The inclusion criteria were:

1. age $18-75$ years; and

2. diagnosis of the neurotic spectrum disorder (F4X.X), mild or moderate depressive disorder (F32.0, F32.1, F33.0, F33.1, and F34.1) with or without comorbidity with personality disorders (F60.0-F60.9 or F61) according to ICD-10. ${ }^{1}$

We used ICD- $10^{1}$ criteria because they are official diagnostic criteria in the Czech Republic, and psychiatrists and psychologists are very well trained to use them. The second reason was that $D S M-5^{2}$ criteria were printed later than our study started. Patients suffering from any psychotic, bipolar, or organic mental disorder were excluded. The diagnoses were confirmed by two independent psychiatrists.

\section{Measurements}

Patients who agreed to participate in the study signed an informed consent form and completed several scales. The following scales were completed at the start and the end of the treatment:

1. Clinical Global Impression (CGI). ${ }^{44}$ The scale focuses on the global evaluation of the severity of present psychopathology. The evaluation can be objective (objCGI) when a psychiatrist assesses it. The subjective assessment (subjCGI) is based on the patient's assessment. The reliability of the scale is satisfactory. ${ }^{45}$

2. Beck Anxiety Inventory (BAI). ${ }^{46}$ The scale is based on 21 items about anxiety symptoms on a 4-point Likert scale. The patient chooses perceived symptoms and their severity during the last week. According to Steer, ${ }^{47} \mathrm{BAI}$ shows excellent psychometric characteristics.

3. Beck Depression Inventory, second edition (BDI-II). ${ }^{48}$ The scale also includes 21 items, about depressive symptoms, in which patients choose perceived symptoms and their severity during the last week. Cronbach's alpha is 0.86 for a psychiatric population and 0.81 for a nonpsychiatric population. ${ }^{49}$

The following questionnaires were used only at the start of the treatment:

1. COPE Inventory. ${ }^{50}$ The questionnaire includes 60 items based on a 4-point scale focusing on the usual frequency of the use of described reactions to stressful events. The inventory covers 15 different coping strategies that vary from emotion-focused to problem-focused and from adaptive to less adaptive. The Cronbach's alphas for the subscales measuring specific coping strategies range from 0.45 (Mental disengagement) to 0.92 (Turning to religion)..$^{50}$

2. Adult Dispositional Hope Scale (ADHS). ${ }^{39}$ This scale consists of 12 items - four of them are focused on pathway thinking (ie, the ability to find ways to achieve desired goals); another four are related to agency (ie, a sense of inner motivation and will to achieve goals); and the last four items are distractors. Patients choose one of the eight points on a scale according to the level of agreement with each statement. The Cronbach's alpha for the English version of the scale may be in the range $0.74-0.84 .{ }^{39}$

3. DES. ${ }^{51}$ The scale describes 28 dissociative experiences, and patients mark a spot on a $10 \mathrm{~cm}$ line according to the frequency of experiencing the symptoms. Besides the overall scale score, a pathological dissociation can also be evaluated by using DES Taxon. This subscale consists of eight out of the 28 DES items (items 3, 5, 7, 8, 12, 13, 22, and 27). ${ }^{52}$ The Czech version of the scale is comparable to the original version in terms of its test-retest reliability, validity, and factor structure. ${ }^{53}$ The Cronbach's alpha for the scale is $0.95 .{ }^{13}$

\section{Methods of the treatment}

All patients were hospitalized in the psychotherapeutic department of the Department of Psychiatry at the University Hospital Olomouc, Olomouc, Czech Republic for 6 weeks. They were treated by group CBT or short psychodynamic therapy. Patients attended the 30 group sessions and five individual sessions. The assignment of the patients to the 
CBT or short psychodynamic therapy was not randomized. The psychotherapeutic group protocol also included drama therapy, progressive muscle relaxation, mental imagery, and physical activities. All patients were treated with usual doses of previously used medication for anxiety and depressive disorders. The strategies used for the treatment corresponded with the Czech National Guidelines for the treatment of psychiatric patients. ${ }^{54,55}$

\section{Statistics}

Statistics were calculated using Prism statistical software (GraphPad Prism version 5.0), SPSS 17.0, and G*Power 3.1. ${ }^{56}$ The applied statistical methods were descriptive statistics for the demographic data, average scores, and a character of data distribution. Differences between scale scores measured at the start and the end of the treatment were calculated by parametric or nonparametric paired $t$-tests. Differences in the declines of the scale scores in patients with and without comorbid depression and patients undergoing the group CBT or short psychodynamic therapy were calculated by two-way analysis of variance and two-way analysis of variance for repeated measures, respectively. Relationships between treatment and other factors were calculated by parametric or nonparametric correlations and a multiple stepwise regression analysis. The effect size was identified by Cohen's $f^{2}$. The threshold for the statistical significance was set at $5 \%$.

\section{Ethics}

The research was conducted in accordance with the latest version of the Helsinki Declaration and the Guideline for Good Clinical Practice. ${ }^{57}$ The study was approved by the local ethical committee.

\section{Results Subjects}

Participation in the study was offered to 89 patients. Thirteen patients refused to participate. Seventy-six patients completed both the program and the scales.

Fifty-eight patients (76.3\%) were women; the mean age was $40.20 \pm 12.85$ years. Eleven $(14.7 \%)$ patients had primary education level, 22 (29.3\%) had finished lower vocational training, 33 (44.0\%) had completed secondary school $(n=22$, $29.3 \%$ ), and eight patients (10.7\%) had graduated from university. One patient had not finished elementary school, and another patient did not state the level of education. Most patients were working as employees or were self-employed $(\mathrm{n}=38,50.0 \%), 26$ patients were unemployed $(34.2 \%)$, and a minority of the individuals were taking disability rent $(n=4,5.3 \%)$ or old age pension $(n=4,5.3 \%)$ at the time of the measurement. As for the partnership status, most patients were married $(n=32,42.1 \%)$, a substantial number of the patients were single $(n=26,34.2 \%)$ or divorced $(n=17$, $22.4 \%$ ), and there was one widow.

The patients were divided into two main groups - the individuals with a primary neurotic disorder $(n=59,77.6 \%)$ and the individuals with a primary depressive disorder $(n=17$, $22.4 \%)$. Fifty-two patients (68.4\%) suffered from a comorbid disorder, out of which 23 patients (30.3\%) were diagnosed with a personality disorder (Table 1 ).

Out of 76 patients, 35 individuals underwent short psychodynamic therapy, and 41 subjects participated in CBT. There was not a significant difference in the age of the patients undergoing the short psychodynamic therapy or CBT, although the individuals attending CBT were somewhat younger (mean age $=43.00 \pm 11.81$ and $37.80 \pm 13.35$ years, respectively; unpaired $t$-test: not significant [ns]). There was also not a significant difference in respect of sex, in spite of considerably more men undergoing CBT (there were 29 women and six men in the short psychodynamic therapy, while CBT was attended by 29 women and 12 men; chi-square: ns). The patients from both groups also did not significantly differ in the initial levels of anxiety (BAI $=23.71 \pm 12.47$ and $22.98 \pm 11.85$, respectively; unpaired $t$-test: ns), depression (BDI-II $=23.83 \pm 11.62$ and $25.78 \pm 10.87$, respectively; unpaired $t$-test: ns), subjective evaluation of the severity of mental health issues (subjCGI $=4.58 \pm 1.30$ and $4.73 \pm 1.10$, respectively; unpaired $t$-test: ns), or objective evaluation of the severity of mental health issues (objCGI $=4.66 \pm 0.97$ and $4.80 \pm 1.11$, respectively; unpaired $t$-test: ns).

\section{Medication}

The patients were preferably treated by the medication already prescribed by their outpatient psychiatrist. They were using standard doses of antidepressants, antipsychotics, or anxiolytics. Details about types of drugs used by the patients and their combinations are presented in Table 1. The mean dose of antidepressant was $50.62 \mathrm{mg}$ of paroxetine equivalent at the start of the treatment (used by 65 patients) and $47.18 \mathrm{mg}$ of paroxetine equivalent at the end of the treatment (used by 71 patients). The mean dose of anxiolytic was $1.08 \mathrm{mg}$ of alprazolam equivalent at the start of the treatment (used by 24 patients) and $0.50 \mathrm{mg}$ of alprazolam equivalent at the end of the treatment (used by 12 patients). Finally, the mean dose of atypical antipsychotic was $1.52 \mathrm{mg}$ of risperidone equivalent at the start of the treatment (used by 15 patients) 


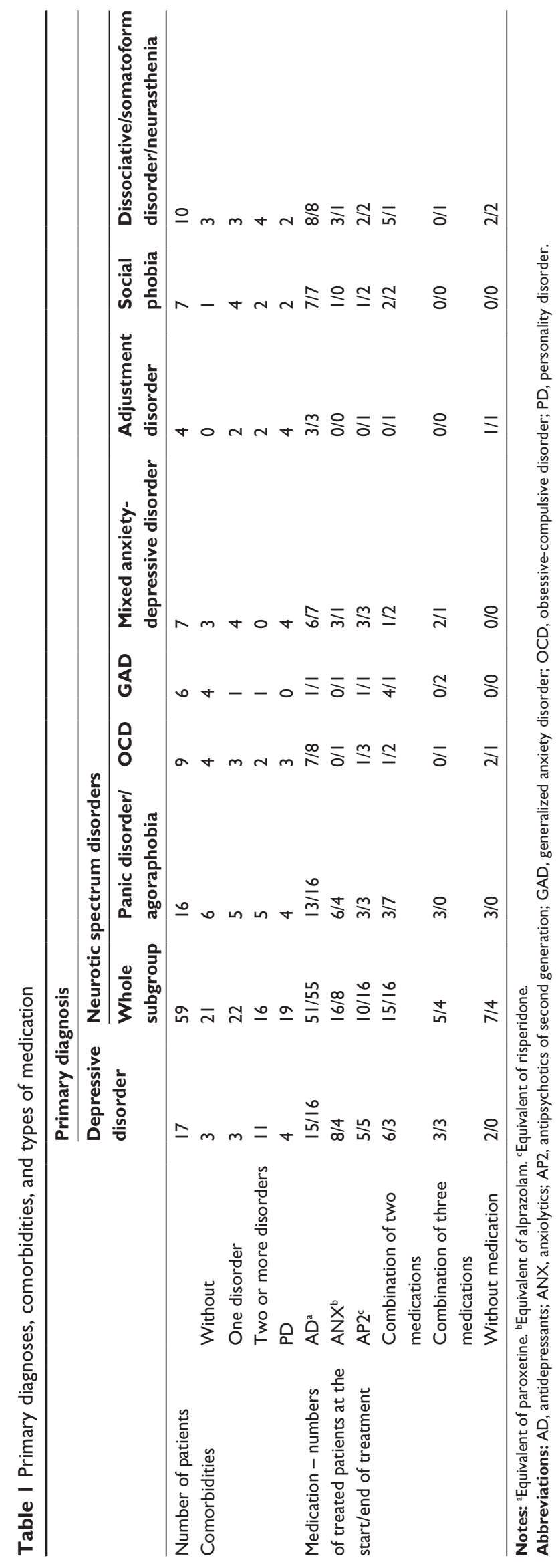

and $1.49 \mathrm{mg}$ of risperidone equivalent at the end of the treatment (used by 21 patients).

The mean doses of antidepressants used at the beginning of the therapy did not statistically significantly differ in patients with a primary neurotic disorder and the group of the patients with primary depression $(46.73 \pm 34.54 \mathrm{mg}$ versus $60.00 \pm 38.24 \mathrm{mg}$ of paroxetine equivalent, MannWhitney test: $U=326$; ns). However, the individuals with a primary depressive disorder were taking significantly higher doses of antidepressants at the end of the treatment than the patients with a primary neurotic disorder (64.71 $\pm 40.94 \mathrm{mg}$ versus $41.64 \pm 28.01 \mathrm{mg}$ of paroxetine equivalent, Mann-Whitney test: $U=307.5 ; P<0.05$ ). There were no significant differences in the doses of antipsychotics and anxiolytics either at the beginning or the end of the therapy.

The mean scores for all scales measuring the severity of the disorder (BAI, BDI-II, subjCGI, and objCGI) significantly decreased after the treatment (Figure 1).

There were no statistically significant differences between treatment groups pretreatment in rating scales. There were several statistically significant differences between the therapeutic changes reached by the therapeutic approaches: the patients treated with CBT improved significantly more in depressive symptoms (BDI-II) and overall state of psychopathology (objCGI) than the patients treated with short psychodynamic therapy (Table 2). There were no significant differences between the other measures of the therapeutic change (BAI or subjCGI) of the patients who underwent either short-term psychodynamic therapy or CBT (Table 2).

\section{Relationship between coping strategies and therapeutic change}

The overall COPE Inventory score did not correlate with the primary outcome measures - the relative or absolute change in objCGI (Table 3). Despite this fact, several subscores of the inventory significantly correlated with the outcome measures Positive reinterpretation and growth, Active coping, Use of emotional social support, Suppression of competing activities, and Planning (all of them are considered to be active coping strategies). These subscales correlated positively with the extent of therapeutic change. The subscales Behavioral disengagement and Substance use (avoidant strategies) correlated negatively with the therapeutic change. The only significant correlation with the secondary therapeutic outcome measure (subjCGI) was between the therapeutic change (in subjCGI) and Acceptance. 


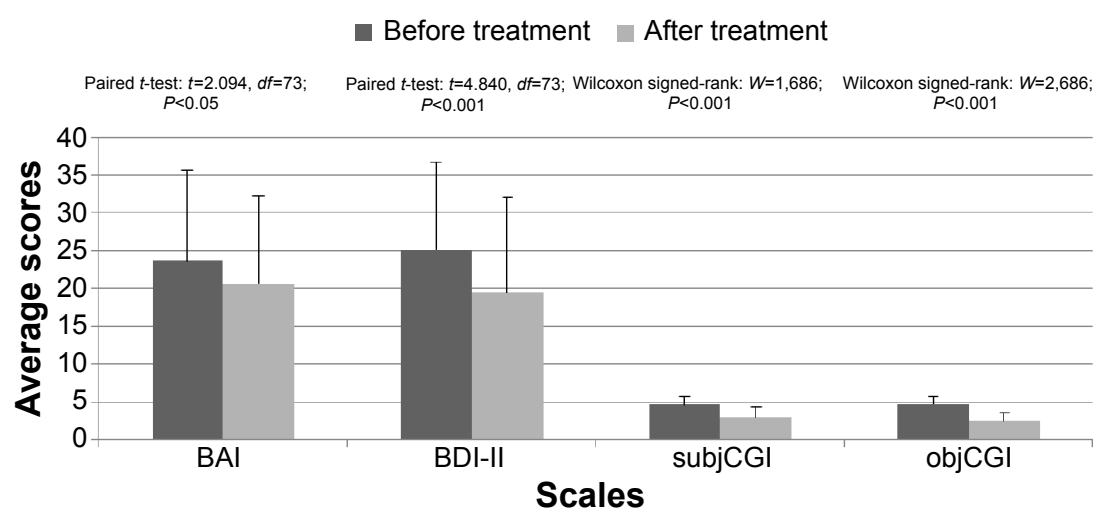

Figure I The mean overall scores on the scales at the beginning and end of treatment.

Abbreviations: BAI, Beck Anxiety Inventory; BDI-II, Beck Depression Inventory, second edition; df, degrees of freedom; objCGI, objective Clinical Global Impression; subjCGI, subjective Clinical Global Impression.

\section{Relationship between hope and therapeutic change}

The overall score of ADHS was highly positively correlated with the relative and absolute change in the primary outcome measure, objCGI (Table 2), but did not correlate with the secondary outcome measure (subjCGI).

\section{Relationship between dissociation and therapeutic change}

The DES scores were highly negatively correlated with objCGI (both relative and absolute change). The change in subjCGI did not significantly correlate with the DES scores (Table 2).

\section{Relationship between comorbid depression or personality disorders and therapeutic change}

When comparing the overall scores of BAI, objCGI, and subjCGI at the start of the treatment, there were no significant differences between the group of neurotic patients with a comorbid depressive disorder and the group without depression. There was a statistically significant difference between the depressed and non-depressed group in the score of depressive symptoms (measured by BDI-II). During the treatment, the depressive and nondepressive groups differed in the change of the anxiety symptoms (BAI) and the overall level of psychopathology evaluated by a physician (objCGI scores), but not in the subjective evaluation of own mental state (subjCGI scores) (Table 4).

The patients with a personality disorder compared to patients without the comorbidity showed more symptoms of depression (BDI-II) and worse mental state (Table 3). When comparing changes in both groups during the treatment, there were no statistically significant differences between the groups in the changes in BAI, BDI-II, or subjCGI. The only significant difference was in the objCGI score - the mental state of the patients with a comorbid personality disorder

Table 2 Changes in the rating scales in patients treated with short psychodynamic therapy or cognitive behavioral therapy

\begin{tabular}{|c|c|c|c|}
\hline Scales and subscales & $\begin{array}{l}\text { Short-term psychodynamic } \\
\text { psychotherapy }\end{array}$ & Statistics & $\begin{array}{l}\text { Cognitive behavioral } \\
\text { therapy }\end{array}$ \\
\hline BAI - before & $23.7 I \pm 12.47(n=35)$ & & $22.98 \pm I I .85(n=4 I)$ \\
\hline BAI - after & $19.54 \pm 1 \mid .86(n=35)$ & & $21.27 \pm I \mid .20(n=4 I)$ \\
\hline Two-way RM ANOVA & & $F=1.643, d f=35 ; \mathrm{ns}$ & \\
\hline BDI-II - before & $23.83 \pm 11.62(n=35)$ & & $25.78 \pm 10.87(n=39)$ \\
\hline BDI-II - after & $19.31 \pm 14.2(n=35)$ & & $19.69 \pm 11.15(n=39)$ \\
\hline Two-way RM ANOVA & & $F=2.075, d f=35 ; \boldsymbol{P}<0.0005$ & \\
\hline subjCGI - before & $4.58 \pm 1.30(n=33)$ & & $4.73 \pm 1.10(n=37)$ \\
\hline subjCGI - after & $3.00 \pm 1.56(n=33)$ & & $2.97 \pm 1.26(n=37)$ \\
\hline Two-way RM ANOVA & & $F=0.4195, d f=33 ;$ ns (significance $0.08 \mathrm{I}$ ) & \\
\hline objCGI - before & $4.66 \pm 0.97(n=35)$ & & $4.80 \pm 1.11(n=39)$ \\
\hline objCGI - after & $2.71 \pm 1.10(n=35)$ & & $2.44 \pm 0.91 \quad(n=39)$ \\
\hline Two-way RM ANOVA & & $F=I .88, d f=35 ; \boldsymbol{P}<\mathbf{0 . 0 0 I}$ & \\
\hline
\end{tabular}

Note: The bold values denote statistical significance.

Abbreviations: ANOVA, analysis of variance; BAI, Beck Anxiety Inventory; BDI-II, Beck Depression Inventory, second edition; df, degrees of freedom; ns, non-significant; objCGI, objective Clinical Global Impression; RM, repeated measures; subjCGI, subjective Clinical Global Impression. 
Table 3 Coping strategies, hope, and dissociation - the mean scores of scales for the whole group and their relationship with the outcome measures

\begin{tabular}{|c|c|c|c|c|c|}
\hline Scales and subscales & $\begin{array}{l}\text { Mean } \pm \text { standard } \\
\text { deviation }\end{array}$ & $\begin{array}{l}\text { Correlation } \\
\text { with objCGI } \\
\text { relative change }\end{array}$ & $\begin{array}{l}\text { Correlation } \\
\text { with objCGI } \\
\text { difference }\end{array}$ & $\begin{array}{l}\text { Correlation } \\
\text { with subjCGI } \\
\text { relative change }\end{array}$ & $\begin{array}{l}\text { Correlation } \\
\text { with subjCGI } \\
\text { difference }\end{array}$ \\
\hline COPE Inventory - overall score & $148.6 \pm 18.78$ & $0.160^{\mathrm{s}} ; \mathrm{ns}$ & $0.075^{\text {s; }}$ ns & $0.046^{\text {s; }}$ ns & $0.014^{\text {s; }} ; \mathrm{ns}$ \\
\hline Positive reinterpretation and growth & $10.05 \pm 3.18$ & $0.416^{5, * * *}$ & $0.190^{\mathrm{s}} ; \mathrm{ns}$ & $0.039^{\text {s; }}$ ns & $-0.078^{\mathrm{s}} ; \mathrm{ns}$ \\
\hline Mental disengagement & $10.5 \pm 2.32$ & $-0.09 I^{\mathrm{s}} ; \mathrm{ns}$ & $-0.168^{\mathrm{s}} ; \mathrm{ns}$ & $-0.089^{\text {s; }}$ ns & $-0.146^{\mathrm{s}} ; \mathrm{ns}$ \\
\hline Focus on and venting of emotions & $11.24 \pm 2.40$ & $-0.213^{\mathrm{s}} ; \mathrm{ns}$ & $-0.252^{\mathrm{s}, *}$ & $-0.022^{\mathrm{s}} ; \mathrm{ns}$ & $0.069^{\mathrm{s}} ; \mathrm{ns}$ \\
\hline Use of instrumental social support & $11.16 \pm 3.10$ & $0.109^{\text {s; }}$ ns & $0.048^{\mathrm{s}} ; \mathrm{ns}$ & $0.021^{\text {s; }}$ ns & $0.030^{\mathrm{s}} ; \mathrm{ns}$ \\
\hline Active coping & $11.24 \pm 3.12$ & $0.336^{\mathrm{s}, * *}$ & $0.213^{\mathrm{s}} ; \mathrm{ns}$ & $-0.069^{\text {s; }}$ ns & $-0.030^{\mathrm{s}} ; \mathrm{ns}$ \\
\hline Denial & $8.61 \pm 2.45$ & $-0.110^{\mathrm{s}} ; \mathrm{ns}$ & $-0.062^{\mathrm{s}} ; \mathrm{ns}$ & $0.110^{\text {s; }}$ ns & 0.129 ; ns \\
\hline Religious coping & $6.72 \pm 3.69$ & $0.089^{\text {s; }}$ ns & $0.125^{\text {s; }}$ ns & $0.084^{\mathrm{s}} ; \mathrm{ns}$ & $0.120^{\text {s; }}$ ns \\
\hline Humor & $7.05 \pm 3.14$ & $0.194^{\mathrm{s}} ; \mathrm{ns}$ & $0.091^{\text {s; }}$ ns & $0.037^{\text {s; }}$ ns & $-0.027^{\mathrm{s}} ; \mathrm{ns}$ \\
\hline Behavioral disengagement & $10.61 \pm 2.85$ & $-0.307^{\mathrm{s}, * *}$ & $-0.179^{\text {s; }}$ ns & $0.054^{\mathrm{s}} ; \mathrm{ns}$ & $0.099^{\text {s; }}$ ns \\
\hline Restraint & $10.62 \pm 2.16$ & $0.065^{\mathrm{s}} ; \mathrm{ns}$ & $0.031^{\text {s; }}$ ns & $-0.008^{\mathrm{s}} ; \mathrm{ns}$ & $-0.00 I^{\mathrm{s}} ; \mathrm{ns}$ \\
\hline Use of emotional social support & $10.67 \pm 3.33$ & $0.245^{5, *}$ & $0.080^{\mathrm{s}} ; \mathrm{ns}$ & $0.069^{\text {s; }}$ ns & $0.048^{\mathrm{s}} ; \mathrm{ns}$ \\
\hline Substance use & $8.47 \pm 4.20$ & $-0.3 \mid 4^{\mathrm{s}, * *}$ & $-0.154^{\mathrm{s}} ; \mathrm{ns}$ & $0.144^{\mathrm{s}} ; \mathrm{ns}$ & $0.154^{\mathrm{s}} ; \mathrm{ns}$ \\
\hline Acceptance & $10.47 \pm 2.94$ & $0.133^{\text {s; }} ; \mathrm{ns}$ & $0.058^{\text {s; }} ; \mathrm{ns}$ & $-0.140^{\mathrm{s}} ; \mathrm{ns}$ & $-0.236^{\mathrm{s}, *}$ \\
\hline Suppression of competing activities & $10.12 \pm 2.92$ & $0.356^{5, * *}$ & $0.235^{\mathrm{s}, *}$ & $-0.126^{\mathrm{s}} ; \mathrm{ns}$ & $-0.105^{\mathrm{s}} ; \mathrm{ns}$ \\
\hline Planning & $|1.4| \pm 2.85$ & $0.286^{\mathrm{s}, *}$ & $0.082^{\text {s; }}$ ns & $-0.088^{\mathrm{s}} ; \mathrm{ns}$ & $-0.054^{\mathrm{s}} ; \mathrm{ns}$ \\
\hline ADHS - overall score & $34.74 \pm 11.94$ & $0.4 I I^{\mathrm{S}, * * * *}$ & $0.235^{\mathrm{s}, *}$ & $0.082^{\mathrm{s}} ; \mathrm{ns}$ & $0.038^{\text {s; }}$ ns \\
\hline Pathway thinking & $18.68 \pm 6.24$ & $0.407^{5, * * *}$ & $0.219^{5} ; \mathrm{ns}$ & $0.075^{\mathrm{s}} ; \mathrm{ns}$ & $0.033^{\mathrm{s}} ; \mathrm{ns}$ \\
\hline Agency & $16.05 \pm 6.82$ & $0.357^{\mathrm{s}, * * *}$ & $0.212^{\mathrm{s}} ; \mathrm{ns}$ & 0.079 ; $;$ ns & $0.026^{\mathrm{s}} ; \mathrm{ns}$ \\
\hline DES & $|4.1| \pm \mid 3.84$ & $-0.413^{\mathrm{s}, * * *}$ & $-0.237^{\text {s; }}$ ns & $-0.133^{\mathrm{s}} ; \mathrm{ns}$ & $-0.160^{\mathrm{s}} ; \mathrm{ns}$ \\
\hline DES Taxon & $8.30 \pm 12.49$ & $-0.304^{\mathrm{s}, * * *}$ & $-0.203^{\mathrm{s}} ; \mathrm{ns}$ & $-0.235^{\mathrm{s}, *}$ & $-0.234^{\mathrm{s}} ; \mathrm{ns}$ \\
\hline
\end{tabular}

Notes: 'Spearman's $r$. $* P<0.05 ; * * P<0.01$; $* * * P<0.001$. The bold values denote statistical significance.

Abbreviations: ADHS, Adult Dispositional Hope Scale; DES, Dissociative Experiences Scale; ns, non-significant; objCGI, objective Clinical Global Impression; subjCGI, subjective Clinical Global Impression.

improved during the treatment slightly more than that of their counterparts without this comorbidity (Table 4).

\section{Multiple regression of the relationship between treatment change and specific psychological factors}

Because of the relatively high number of the factors significantly correlating with the primary outcome measures, we decided to apply a multiple regression (precisely, a backward stepwise regression analysis) to find out which factors were the most significant predictors of the therapeutic outcome. The dependent variable was the objCGI change; the independent variables were the factors that correlated the strongest with the dependent variable. The chosen independent variables were: the overall score of ADHS, the overall rating of DES, and several subscales of the COPE Inventory - Active coping, Planning, Substance use, Behavioral disengagement, and Acceptance. These variables explained a small part of the objCGI change variance ( $R$-square adjusted $=0.160$, significance $=0.012$ ). The only significant predictors of the treatment efficacy were the overall level of hope (beta $=0.283$, standard error $(\mathrm{SE})=0.008$, significance $=0.013$ ) and the overall level of dissociation (beta $=-0.316, \mathrm{SE}=0.007$, significance $=0.006)$ (Figures 2 and 3$)$. To determine the effect size, we computed Cohen's $f^{2}$. Its value $(0.28)$ indicated that the effect size of the final model with the two predictors was medium. ${ }^{58}$

\section{Discussion}

The results of our study show that the therapeutic change during an intensive 6-week therapeutic inpatient program was significantly influenced by several psychological variables. The multiple regression analysis pinpointed two factors that contributed to the treatment efficacy the most significantly. As expected, the first factor was hope. The concept of hope we used is based on the theory of Snyder, ${ }^{39}$ who posited that hope is a feeling emerging under certain conditions in goaldirected situations. In the context of the combined inpatient program, the more patients know what they want to achieve during the hospitalization, and are active and motivated, the more successful the treatment is. It should be mentioned that we had to exclude the coping strategy "positive reinterpretation and growth" from the regression analysis due to the high correlation with hope measured by the ADHS. Through this step, we avoided the statistical redundancy stemming from multicollinearity. ${ }^{59}$ As was already stated 
Table 4 The mean overall scores at the start and end of treatment in patients with and without comorbid depressive disorder and in patients with and without comorbid personality disorders

\begin{tabular}{|c|c|c|c|c|c|c|}
\hline $\begin{array}{l}\text { Scales before and } \\
\text { after treatment }\end{array}$ & Depressive & Statistics & $\begin{array}{l}\text { Non- } \\
\text { depressive }\end{array}$ & $\begin{array}{l}\text { With } \\
\text { comorbid } \\
\text { personality } \\
\text { disorders }\end{array}$ & Statistics & $\begin{array}{l}\text { Without } \\
\text { comorbid } \\
\text { personality } \\
\text { disorders }\end{array}$ \\
\hline Number of patients & 17 & & 52 & 21 & & 55 \\
\hline $\mathrm{BAI}$ - before & $22.88 \pm 12.24$ & & $23.85 \pm 11.98$ & $26.57 \pm|3.5|$ & & $22.50 \pm 11.22$ \\
\hline BAI - after & $21.81 \pm 10.55$ & & $20.28 \pm 11.92$ & $26.81 \pm 12.75$ & & $18.15 \pm 10.21$ \\
\hline Two-way RM ANOVA & & $F=2.424, d f=16 ; P<0.005$ & & & $F=I .588, d f=21 ; n s$ & \\
\hline BDI-II - before & $31.38 \pm 11.12$ & & $23.50 \pm 11.06$ & $30.7 I \pm 10.94$ & & $23.03 \pm 11.03$ \\
\hline BDI-II - after & $26.31 \pm 12.53$ & & $17.64 \pm 12.06$ & $27.67 \pm 12.90$ & & $16.28 \pm 11.02$ \\
\hline Two-way RM ANOVA & & $F=3.548, d f=23 ; P<0.0 I$ & & & $F=2.2270, d f=2 I ; n s$ & \\
\hline subjCGI - before & $4.81 \pm 0.75$ & & $4.53 \pm 1.32$ & $4.91 \pm 1.34$ & & $4.46 \pm 1.16$ \\
\hline subjCGI - after & $3.56 \pm 1.41$ & & $2.82 \pm 1.34$ & $2.95 \pm 1.31$ & & $3.00 \pm 1.41$ \\
\hline Two-way RM ANOVA & & $F=0.7367, d f=16 ; n s$ & & & $\mathrm{~F}=0.5 \mathrm{I} 7, \mathrm{df}=2 \mathrm{I} ; \mathrm{ns}$ & \\
\hline objCGI - before & $4.7 I \pm 0.85$ & & $4.74 \pm 1.09$ & $5.43 \pm 1.12$ & & $4.46 \pm 0.86$ \\
\hline objCGI - after & $2.88 \pm 0.86$ & & $2.47 \pm 1.04$ & $3.20 \pm 1.01$ & & $2.33 \pm 0.91$ \\
\hline Two-way RM ANOVA & & $F=0.2143, d f=17 ; P<0.0001$ & & & $F=1.414, d f=21 ; P<0.05$ & \\
\hline
\end{tabular}

Note: The bold values denote statistical significance.

Abbreviations: ANOVA, analysis of variance; BAI, Beck Anxiety Inventory; BDI-II, Beck Depression Inventory, second edition; df, degrees of freedom; ns, non-significant; objCGI, objective Clinical Global Impression; RM, repeated measures; subjCGI, subjective Clinical Global Impression.

by Snyder, ${ }^{39}$ hope is tightly connected to the ability to learn from failures and stressful life experiences. Through this process of learning, hope and self-efficacy are built. Thus, it is not only the emotion of hope that predicts better treatment outcomes. A whole complex of thoughts and active goal-directed actions plays a significant role in the treatment efficacy of patients with neuroses. The complex nature of hope might also be a possible explanation for the fact that all of the significantly correlating coping strategies faded away in the multiple regressions and hope and dissociation were

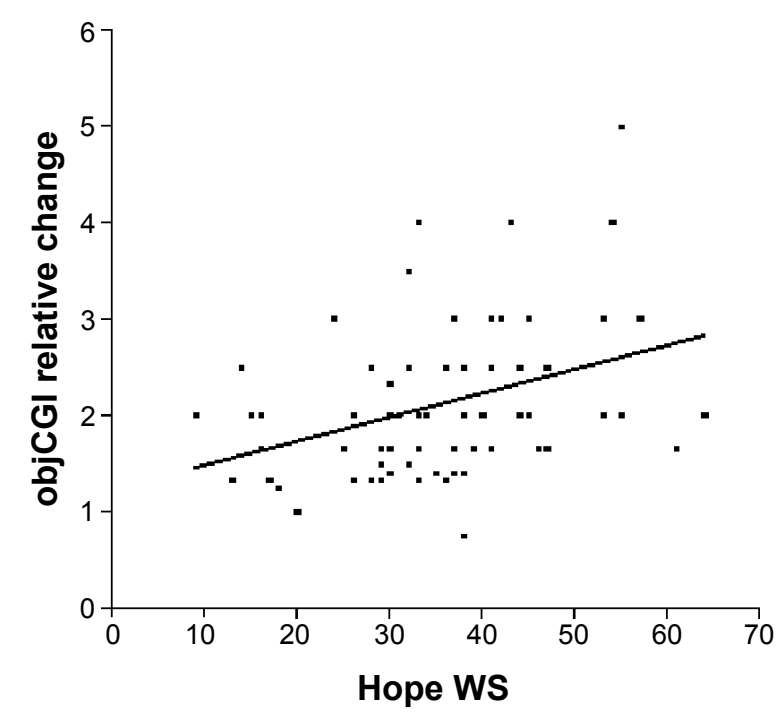

Figure 2 Linear regression of the overall score of ADHS (WS) and the relative change measured by objCGI.

Notes: $F=10.71$, DFn, DFd $=1.000,69.00 ; P<0.005$.

Abbreviations: ADHS, Adult Dispositional Hope Scale; DFd, degree of freedom for the denominator; DFn, degree of freedom for the numerator; objCGI, objective Clinical Global Impression; WS, whole score. the only significant predictors. Simply put, active coping, search for social support, suppression of competing activities, and planning are all facets of hopeful thinking and behavior. They are both manifestations and consequences of hope, as well as its predictors.

Apart from hope, the multiple regression analysis showed only one psychological factor significantly predicting the treatment outcomes - dissociation. The patients who tended to dissociate in reaction to unbearable stress improved significantly less during the treatment than their colleagues,

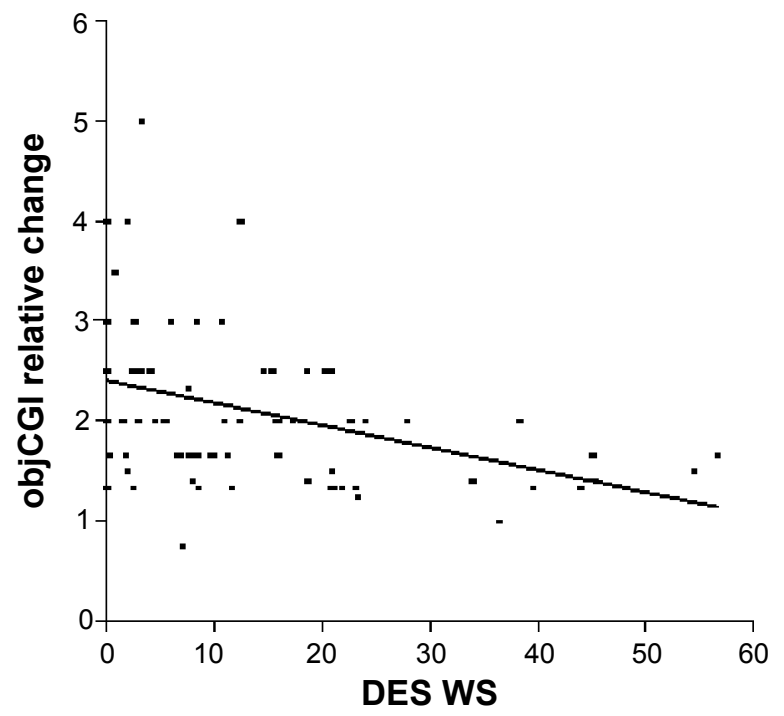

Figure 3 Linear regression between DES WS and the relative change measured by objCGl.

Notes: $F=11.74, D F n, D F d=1.000,71.00 ; P<0.001$.

Abbreviations: DES WS, Dissociative Experiences Scale whole score; DFd, degree of freedom for the denominator; DFn, degree of freedom for the numerator; objCGI, objective Clinical Global Impression. 
who did not have such tendencies. This result is in accordance with studies from several other authors, ${ }^{9,18}$ but not with every study on this topic. ${ }^{28,60}$ The reason for the differences in the findings on the role of dissociation in the treatment outcomes might be in different clinical samples examined and dissociative experiences considered. For example, Halvorsen et $\mathrm{al}^{60}$ studied only patients with PTSD.

There were also several avoidant strategies, namely behavioral disengagement and substance use, which were significantly connected to the poorer treatment outcomes of the patients with neurotic disorders. However, the effect of these coping strategies was suppressed during the multiple regression analysis. These results suggest that therapeutic interventions, which would focus on the increasing of hopeful thinking and behavior and decreasing the level of dissociation, might be useful in the treatment-resistant patients suffering from neurotic disorders.

Our study also showed that patients with comorbid personality disorders were more depressed at the start of the treatment than the patients without these comorbidities. However, both groups of the patients substantially improved during the treatment, and the relative change of the depressive symptoms was comparable for both groups. Nevertheless, the overall mental state of the patients with comorbid personality disorders improved considerably less during the hospitalization when compared to the patients without this comorbidity. Several studies have also reported poorer treatment outcomes in patients with neurotic disorders and comorbid personality disorders. For example, Telch et $\mathrm{al}^{61}$ found that patients with a panic disorder and a comorbid cluster $\mathrm{C}$ personality disorder improve considerably less during psychotherapy than individuals without this comorbidity. Thiel et al, ${ }^{62}$ partly supported by Steketee et al, ${ }^{63}$ stated that the psychotherapeutic treatment of OCD is significantly less effective when patients suffer from a comorbid schizotypal or narcissistic personality disorder.

In our study, the comorbidity with depression was also shown to be a factor contributing to the treatment resistance of the neurotic patients, as the patients without comorbid depression profited significantly more from the treatment than the patients with this comorbidity. This finding is supported by Overbeek et $\mathrm{al}^{64}$ who showed similar results in a sample of patients with OCD. At the same time, it is quite inconsistent with the outcome of the study by Steketee et $\mathrm{al}^{63}$ according to whom, the presence of depressive disorders predicts better treatment outcomes in patients with OCD but depressive symptoms per se do not. Further research on this topic may be needed.

The study has several limitations. The group of the patients who participated in the study was relatively small. It was also heterogeneous for firm conclusions about specific predictors of outcome. The participants were diagnosed with various neurotic spectrum disorders; approximately $22 \%$ suffered from a comorbid depressive disorder and $30 \%$ from a comorbid personality disorder. This prevents the possibility of generalizing the findings to the whole population of patients with neurotic spectrum disorders or specific subgroups of this population. Other studies based on a larger population of patients with more specific neurotic disorders need to be carried out. Another limitation involves the fact that some patients did not fulfill all of the required items in the questionnaire battery. Thus, we may have lacked data from patients who lacked hope and suffered from dissociation most. The prevalent use of the psychodiagnostic methods based on self-evaluation presents another shortcoming of the study. The use of these scales and inventories depends on the ability of introspection of the probands and their willingness to be open in the statements. We also did not include a control group in the study, which is another limitation. It also needs to be mentioned that particular diagnostic groups might respond to intensive treatment differently. The patients were treated with various medications and with two alternative psychotherapeutic approaches, which also needs to be mentioned. Despite this diagnostic and treatment diversity, coping strategies, dissociation, and hope prove to be important factors contributing to treatment efficacy of patients with neurotic disorders.

\section{Conclusion}

Patients who suffer from a neurotic disorder and at the same time prefer to use maladaptive coping strategies, feel hopelessness, and have tendencies to dissociate profit from the combined treatment significantly less than their more active and hopeful counterparts. Because the current methods of the treatment cannot help all patients, and a number of them remain resistant to the treatment, it is necessary to search for alternative therapeutic approaches for improving hope, decreasing dissociation, and teaching adaptive strategies for dealing with stress.

\section{Disclosure}

The authors report no conflicts of interest in this work.

\section{References}

1. World Health Organization. The ICD-10 Classification of Mental and Behavioural Disorders: Clinical Descriptions and Diagnostic Guidelines. Geneva: World Health Organization; 1992. Available from: http:// apps.who.int/iris/handle/10665/37958/. Accessed April 29, 2015.

2. American Psychiatric Association. Diagnostic and Statistical Manual of Mental Disorders, Fifth Edition. DSM-5. Arlington: American Psychiatric Association; 2013.

3. Kessler RC, McGonagle KA, Zhao S, et al. Lifetime and 12-month prevalence of DSM-III-R psychiatric disorders in the United States. Results from the National Comorbidity Survery. Arch Gen Psychiatry. 1994;51:8-19. 
4. Pohl RB, Feltner DE, Fieve RR, Pande AC. Efficacy of pregabalin in the treatment of generalized anxiety disorder: double-blind, placebo-controlled comparison of BID versus TID dosing. $J$ Clin Psychopharmacol. 2005;25(2):151-158.

5. Hooke GR, Page AC. Predicting outcomes of group cognitive behavior therapy for patients with affective and neurotic disorders. Behav Modif. 2002;26(5):648-659.

6. Heldt E, Gus Manfro G, Kipper L, Blaya C, Isolan L, Otto MW. One-year follow-up of pharmacotherapy-resistant patients with panic disorder treated with cognitive-behavior therapy: outcome and predictors of remission. Behav Res Ther. 2006;44(5):657-665.

7. Tyrer P, Seivewright H, Johnson T. The Nottingham Study of Neurotic Disorder: predictors of 12-year outcome of dysthymic, panic and generalized anxiety disorder. Psychol Med. 2004;34:1385-1394.

8. Schat A, van Noorden MS, Noom MJ, et al. Predictors of outcome in outpatients with anxiety disorders: the Leiden routine outcome monitoring study. J Psychiatr Res. 2013;47(12):1876-1885.

9. Praško J, Raszka M, Adamcova K, et al. Predicting the therapeutic response to cognitive behavioral therapy in patients with pharmacoresistant obsessive-compulsive disorder. Neuro Endocrinol Lett. 2009;30(5): 615-623.

10. Dell PF, O'Neil JA, editors. Dissociation and the Dissociative Disorders: DSM-V and Beyond. New York, NY: Routledge; 2009.

11. Ross CA. Borderline personality disorder and dissociation. J Trauma Dissociation. 2007;8:71-80.

12. Watson S, Chilton R, Fairchild H, Whewell P. Association between childhood trauma and dissociation among patients with borderline personality disorder. Aust N Z J Psychiatry. 2006;40:478-481.

13. Bob P. Disociativní projevy a jejich měření. [Dissociative symptoms and their measurement]. Ceska Slov Psychiatr. 2000;6:301-309. Czech.

14. Zlotnick C, Shea MT, Pearlstein T, Simpson E, Costello E, Begin A. The relationship between dissociative symptoms, alexithymia, impulsivity, sexual abuse, and self-mutilation. Compr Psychiatry. 1996;37: 12-16.

15. van Heugten-van der Kloet D, Merckelbach H, Giesbrecht T, Broers N. Night-time experiences and daytime dissociation: a path analysis modeling study. Psychiatry Res. 2014;216(2):236-241.

16. Csikszentmihalyi M. Flow: The Psychology of Optimal Experience. New York: Harper Perennial Modern Classics; 2008.

17. Sar V, Akyuz G, Kugu N, Ozturk E, Ertem-Vehid H. Axis I dissociative disorder comorbidity in borderline personality disorder and reports of childhood trauma. J Clin Psychiatry. 2006;67:1583-1590.

18. Gulsun M, Doruk A, Uzun O, Turkbay T, Ozsahin A. Effect of dissociative experiences on drug treatment of panic disorder. Clin Drug Investig. 2007;27:583-590.

19. Pastucha P, Prasko J, Grambal A, et al. Panic disorder and dissociationcomparison with healthy controls. Neuro Endocrinol Lett. 2009;30(6): 774-778.

20. Prasko J, Raszka M, Diveky T, et al. Obsessive compulsive disorder and dissociation - comparison with healthy controls. Biomed Pap Med Fac Univ Palacky Olomouc Czech Repub. 2010;154(2):179-183.

21. Rufer M, Held D, Cremer J, et al. Dissociation as a predictor of cognitive behavior therapy outcome in patients with obsessive-compulsive disorder. Psychother Psychosom. 2006;75:40-46.

22. Sar V, Tutkun H, Alyanak B, Bakim B, Baral I. Frequency of dissociative disorders among psychiatric outpatients in Turkey. Compr Psychiatry. 2000;41(3):216-222.

23. Pastucha P, Prasko J, Diveky T, et al. Borderline personality disorder and dissociation - comparison with healthy controls. Activitas Nervosa Superior Rediviva. 2009;51(3-4):146-149.

24. Pastucha P, Prasko J, Grambal A, Latalova K, Sigmundova Z, Tichackova A. Dissociative disorder and dissociation - comparison with healthy controls. Neuro Endocrinol Lett. 2009;30(6):769-773.

25. Sar V, Ross C. Dissociative disorders as a confounding factor in psychiatric research. Psychiatr Clin North Am. 2006;29:129-144.

26. Ball S, Robinson A, Shekhar A, Walsh K. Dissociative symptoms in panic disorder. J Nerv Ment Dis. 1997;185:755-760.
27. Seguí J, Márquez M, García L, Canet J, Salvador-Carulla L, Ortiz M. Depersonalization in panic disorder: a clinical study. Compr Psychiatry. 2000;41:172-178.

28. Hagenaars MA, van Minnen A, Hoogduin KA. The impact of dissociation and depression on the efficacy of prolonged exposure treatment for PTSD. Behav Res Ther. 2010;48(1):19-27.

29. Simeon D, Greenberg J, Nelson D, Schmeidler J, Hollander E. Dissociation and posttraumatic stress 1 year after the World Trade Center disaster: follow-up of a longitudinal survey. J Clin Psychiatry. 2005;66(2):231-237.

30. Vásquez DA, de Arellano MA, Reid-Quiñones K, et al. Peritraumatic dissociation and peritraumatic emotional predictors of PTSD in Latino youth: results from the Hispanic family study. J Trauma Dissociation. 2012;13(5):509-525.

31. Najavits LM, Walsh M. Dissociation, PTSD, and substance abuse: an empirical study. J Trauma Dissociation. 2012;13(1):115-126.

32. Briere J, Weathers FW, Runtz M. Is dissociation a multidimensional construct? Data from the Multiscale Dissociation Inventory. $J$ Trauma Stress. 2005;18(3):221-231.

33. LeDoux JE, Gorman JM. A call to action: overcoming anxiety through active coping. Am J Psychiatry. 2001;158(12):1953-1955.

34. Roemer L, Litz BT, Orsillo SM, Wagner AW. A preliminary investigation of the role of strategic withholding of emotions in PTSD.J Trauma Stress. 2001;14:149-156.

35. Feldner MT, Zvolensky MJ, Eifert GH, Spira AP. Emotional avoidance: an experimental test of individual differences and response suppression using biological challenge. Behav Res Ther. 2003;41:403-411.

36. Frank JD. The faith that heals. Johns Hopkins Med J. 1975;137: $127-131$.

37. Snyder CR, Harris C, Anderson JR, et al. The will and the ways: development and validation of an individual-differences measure of hope. J Pers Soc Psychol. 1991;60:570-585.

38. Kwon P. Hope and dysphoria: the moderating role of defense mechanisms. J Pers. 2000;68(2):199-223.

39. Snyder CR, editor. Handbook of Hope: Theory, Measures, and Applications. San Diego, CA: Academic Press; 2000.

40. Snyder CR. Hope theory: rainbows in the mind. Psychol Inq. 2002;13(4): 249-275.

41. Snyder CR. The Psychology of Hope: You Can Get There From Here. New York: The Free Press; 1994.

42. Wolverson Radbourne EL, Clarke C, Moniz-Cook E. Remaining hopeful in early-stage dementia: a qualitative study. Aging Ment Health. 2010;14(4):450-460.

43. Perry BM, Taylor D, Shaw SK. "You've got to have a positive state of mind": an interpretative phenomenological analysis of hope and first episode psychosis. J Ment Health. 2007;16(6):781-793.

44. Guy W. ECDEU Assessment Manual for Psychopharmacology. Rockville: U.S. Department of Health, Education, and Welfare; 1976.

45. Zaider TI, Heimberg RG, Fresco DM, Schneier FR, Liebowitz MR. Evaluation of the clinical global impression scale among individuals with social anxiety disorder. Psychol Med. 2003;33:611-622.

46. Beck AT, Epstein N, Brown G, Steer RA. An inventory for measuring clinical anxiety: psychometric properties. J Consult Clin Psychol. 1988;56(6):893-897.

47. Steer RA. Amount of general factor saturation in the Beck Anxiety Inventory response of outpatients with anxiety disorders. J Psychopathol Behav Assess. 2009;31(2):112-118.

48. Beck AT, Steer RA, Ball R, Ranieri W. Comparison of Beck Depression Inventories-IA and -II in psychiatric outpatients. J Pers Assess. 1996;67(3):588-597.

49. Storch EA, Roberti JW, Roth DA. Factor structure, concurrent validity, and internal consistency of the Beck Depression InventorySecond Edition in a sample of college students. Depress Anxiety. 2004;19(3):187-189.

50. Carver CS, Scheier MF, Weintraub JK. Assessing coping strategies: a theoretically based approach. J Pers Soc Psychol. 1989;56(2): 267-283. 
51. Bernstein EM, Putnam FW. Development, reliability, and validity of a dissociation scale. J Nerv Ment Dis. 1986;174(12):727-735.

52. Waller NG, Ross CA. The prevalence and biometric structure of pathological dissociation in the general population: taxometric and behavior genetic findings. J Abnorm Psychol. 1997;106(4):499-510.

53. Ptacek R, Bob P, Paclt I, et al. Psychobiology of dissociation and its clinical assessment. Neuro Endocrinol Lett. 2007;28(2):191-198.

54. Seifertova D, Prasko J, Hoschl C, Horacek J, editors. Postupy v lecbe psychickych poruch. [Guidelines for the treatment of mental disorders]. Praha: Amepra, Medical Tribune; 2008. Czech.

55. Raboch J, Uhlikova P, Hellerova P, Anders M, Susta P, editors. Psychiatrie: Doporucene postupy psychiatricke pece IV. [Psychiatry: Recommended guidelines for psychiatric treatment IV]. Praha: Psychiatricka Spolecnost, o.s.; 2013. Czech.

56. Faul F, Erdfelder E, Lang AG, Buchner A. G*Power 3: a flexible statistical power analysis program for the social, behavioral, and biomedical sciences. Behav Res Methods. 2007;39:175-191.

57. Guideline for Good Clinical Practice. EMEA; 2002. Available from: http://www.edctp.org/fileadmin/documents/EMEA_ICH-GCP_Guidelines_July_2002.pdf. Accessed April 29, 2015.

58. Ellis PD. The Essential Guide to Effect Sizes: Statistical Power, MetaAnalysis, and the Interpretation of Research Results. Cambridge: Cambridge University Press; 2010.
59. Grimm LG, Yarnold PR, editors. Reading and Understanding Multivariate Statistics. Washington, DC: American Psychological Association; 1995.

60. Halvorsen JØ, Stenmark H, Neuner F, Nordahl HM. Does dissociation moderate treatment outcomes of narrative exposure therapy for PTSD? A secondary analysis from a randomized controlled clinical trial. Behav Res Ther. 2014;57:21-28.

61. Telch MJ, Kamphuis JH, Schmidt NB. The effects of comorbid personality disorders on cognitive behavioral treatment for panic disorder. J Psychiatr Res. 2011;45(4):469-474.

62. Thiel N, Hertenstein E, Nissen C, Herbst N, Külz AK, Voderholzer U. The effect of personality disorders on treatment outcomes in patients with obsessive-compulsive disorders. J Pers Disord. 2013;27(6): 697-715.

63. Steketee G, Siev J, Fama JM, Keshaviah A, Chosak A, Wilhelm S. Predictors of treatment outcome in modular cognitive therapy for obsessive-compulsive disorder. Depress Anxiety. 2011;28(4): 333-341.

64. Overbeek T, Schruers K, Vermetten E, Griez E. Comorbidity of obsessive-compulsive disorder and depression: prevalence, symptom severity, and treatment effect. J Clin Psychiatry. 2002;63(12): $1106-1112$.
Neuropsychiatric Disease and Treatment

\section{Publish your work in this journal}

Neuropsychiatric Disease and Treatment is an international, peerreviewed journal of clinical therapeutics and pharmacology focusing on concise rapid reporting of clinical or pre-clinical studies on a range of neuropsychiatric and neurological disorders. This journal is indexed on PubMed Central, the 'PsycINFO' database and CAS,

\section{Dovepress}

and is the official journal of The International Neuropsychiatric Association (INA). The manuscript management system is completely online and includes a very quick and fair peer-review system, which is all easy to use. Visit http://www.dovepress.com/testimonials.php to read real quotes from published authors. 